\title{
Identification of genes for dimethyl sulfide production in bacteria in the gut of Atlantic Herring (Clupea harengus)
}

\author{
Andrew RJ Curson, Matthew J Sullivan, Jonathan D Todd and Andrew WB Johnston \\ School of Biological Sciences, University of East Anglia, Norwich, UK
}

\begin{abstract}
Phytoplankton are the primary producers of the sulfur-containing compatible solute dimethylsulfoniopropionate (DMSP). These cells are consumed by mesozooplankton, which, in turn, may be eaten by marine vertebrates. From the gut of one such animal, the Atlantic Herring Clupea harengus, we isolated strains of the $\gamma$-proteobacteria Pseudomonas and Psychrobacter that grew on DMSP as sole carbon source, and which produced the environmentally important sulfurous volatile dimethyl sulfide (DMS). In both bacterial genera, this ability was because of the previously identified gene $d d d D$, which specifies an enzyme that liberates DMS from DMSP. DMS production was stimulated by pre-growth of cells on the substrate DMSP. This is the first identification of DMSP-degrading bacteria and their relevant genes in the gut microflora of any vertebrate.

The ISME Journal (2010) 4, 144-146; doi:10.1038/ismej.2009.93; published online 27 August 2009

Subject Category: geomicrobiology and microbial contributions to geochemical cycles

Keywords: $d d d D$; dimethyl sulfide; dimethylsulfoniopropionate; Herring; Pseudomonas; Psychrobacter
\end{abstract}

Microbial dimethyl sulfide (DMS) production is very important in the global sulfur cycle, being the major route for the transfer of sulfur from oceans to atmosphere and then back to the land (Sievert et al., 2007). Further, by acting as cloud condensation nuclei, DMS oxidation products induce cloud formation, reflecting more sunlight to space and affecting the climate (Vallina and Simó, 2007).

Dimethyl sulfide is produced from dimethylsulfoniopropionate (DMSP), a hugely abundant $\left(10^{9}\right.$ tons per annum) compatible solute made by many marine phytoplankton and macroalgae, and a few angiosperms (Sievert et al., 2007). Microbes convert DMSP to DMS by at least three completely different enzymes that cleave DMSP. One of these, DddL, is a DMSP lyase, forming acrylate plus DMS from DMSP, and has thus far only been found in marine $\alpha$-proteobacteria (Curson et al., 2008). Another enzyme, DddP, with no sequence similarity to DddL, occurs in $\alpha$-proteobacteria and also in some fungi, but its mechanism of action is unknown (Todd et al., 2009a). The third system involves an enzyme of Class III acyl CoA transferases, encoded by $d d d D$, which releases DMS from DMSP. This gene occurs not only in marine $\gamma$-proteobacteria, but also in other

Correspondence: AWB Johnston, School of Biological Sciences, University of East Anglia, Earlham Road, Norwich, Norfolk NR4 7TJ, UK.

E-mail: a.johnston@uea.ac.uk

Received 25 May 2009; revised 13 July 2009; accepted 20 July 2009; published online 27 August 2009 bacterial taxa, having been acquired by horizontal gene transfer (Todd et al., 2007, 2009b).

Dimethylsulfoniopropionate-catabolizing bacteria have been isolated from several DMSP-rich environments, including corals, algal blooms, copepods (Acartia tonsa) and intertidal salt marshes (Tang et al., 2001; Yoch, 2002; Raina et al., 2009). Here, we describe, for the first time, the isolation of such bacteria from fish and identify the relevant $d d d$ genes.

The Atlantic Herring (Clupea harengus) feeds on copepod crustaceans, which in turn consume DMSP-containing phytoplankton. We sampled the intestine of one such fish, obtained from the North Sea, using a series of enrichments in DMSP-containing liquid medium, before plating on minimal agar plates with 5-mM DMSP as the sole carbon source. After 3 days at $28{ }^{\circ} \mathrm{C}$, two different colony types were identified. Using the universal bacterial primers $27 \mathrm{~F}$ and $1492 \mathrm{R}$, their $16 \mathrm{~S}$ rRNA genes were cloned and then sequenced; the closest $(99 \%$ identical) relatives were Pseudomonas guineae LMG 24017 (Bozal et al., 2007) and Psychrobacter arenosus R7T (Romanenko et al., 2004). Isolates of both these genera have been obtained from guts of other fish (Hovda et al., 2007) and some DMSproducing strains have been reported (Ansede et al., 2001).

The newly isolated Pseudomonas and Psychrobacter strains were termed J465 and J466, respectively. They were assayed for DMSP-dependent DMS production (Ddd phenotype), by gas chroma- 
tography as in Curson et al. (2008). Both produced large amounts of DMS, whose levels were significantly enhanced when cells were pre-grown with 5-mM DMSP. Thus, as in other bacteria (Yoch, 2002; Todd et al., 2007), their $\mathrm{Ddd}^{+}$phenotype is inducible (Figure 1). Strains J465 and J466 were examined for growth on acrylate and 3-hydroxypropionate, as some other DMSP-catabolizing species can use these compounds (Yoch, 2002), and this latter molecule is one of the earliest catabolites formed after the action of DddD on DMSP (Todd et al., 2009b). Pseudomonas J465 did not grow on either compound, but Psychrobacter J466 grew on 3-hydroxy-propionate as the sole carbon source. Acrylate and 3-hydroxy-propionate can also induce DMS production in some bacteria (Yoch, 2002; Todd et al., 2009b); this was also the case for Psychrobacter J466, but not Pseudomonas J465 (Figure 1).

To identify the relevant genes in these new isolates, genomic libraries of Psychrobacter J466

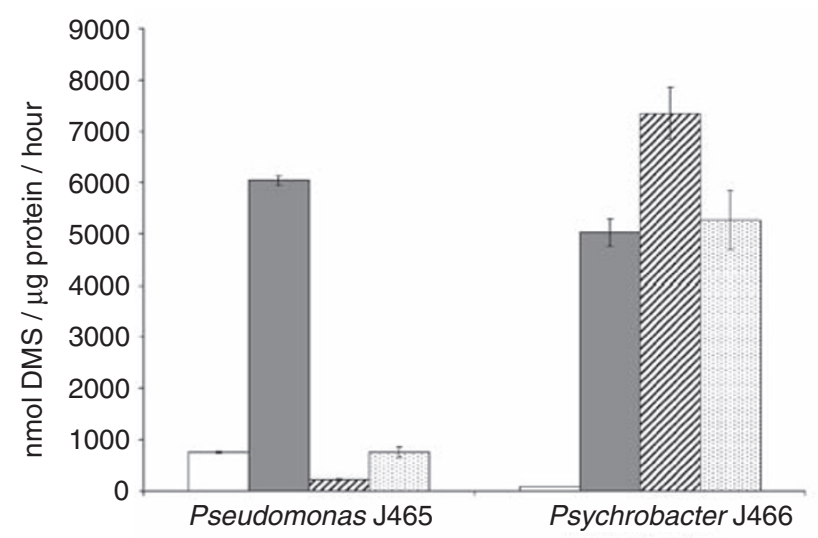

Figure 1 Dimethyl sulfide (DMS) production in Pseudomonas J465 and Psychrobacter J466. Cells were pre-grown with 5-mM dimethylsulfoniopropionate (DMSP) (grey), acrylate (striped), 3-hydroxy-propionate (3-OH-P) (stippled), or no inducer (white). DMS production is in nmol DMS per $\mu$ g protein per hour $\left(\times 10^{5}\right)$ (mean of two independent assays). and Pseudomonas J465 were constructed in the wide host-range cosmid pLAFR3. These cosmids were mobilized into Escherichia coli and screened for any that conferred DMS production to this host (Curson et al., 2008). One such cosmid was identified from each library and their inserts (of approximately $34 \mathrm{~kb}$ (J465) or $21 \mathrm{~kb}$ (J466)) were sequenced. Both contained homologues of $d d d D$, which is responsible for the initial step in DMSP catabolism. The closest homologues to the DddD of Psychrobacter J466 and Pseudomonas J465 were in the $\alpha$-proteobacterium Rhodobacterales HTCC2083 (68\% identical) and the $\gamma$-proteobacterium Marinobacter sp. ELB17 (76\%), respectvely. In addition to $d d d D$, several neighboring genes in Psychrobacter J466 and Pseudomonas J465 resembled those that occur near $d d d D$ in Marinomonas MWYL1 (Todd et al., 2007). These are involved in DMSP transport $(d d d T)$, regulation $(d d d R)$ or in the later stages of DMSP catabolism through $d d d B$ and $d d d C$, which respectively encode polypeptides related to alcohol dehydrogenases and aldehyde dehydrogenases (Figure 2). Psychrobacter J466 also has a gene that encodes a dehydratase-family member (Pfam00378). Pseudomonas J465 has a gene encoding an IclR-type regulator that is likely co-transcribed with $d d d T$, $d d d B, d d d C$ and $d d d R$, and a gene, possibly cotranscribed with $d d d D$, which may encode a major facilitator transporter.

In a direct study of DMSP turnover in Atlantic Menhaden (Brevoortia tyrannus), a close relative of the Herring, approximately $65 \%$ of the DMSP was incorporated into the animals' flesh or was excreted, unmodified, with very little DMS being released when fish were fed DMSP-containing algae (Hill and Dacey, 2006). The fate of the remaining $35 \%$ is unknown, but could be due to bacterial catabolism in one of two ways. First, the DMS formed by $\mathrm{Ddd}^{+}$bacteria may be catabolized by other bacteria that use DMS as a substrate (Schäfer, 2007). Second, another route for DMSP catabolism involves DMSP demethylation,

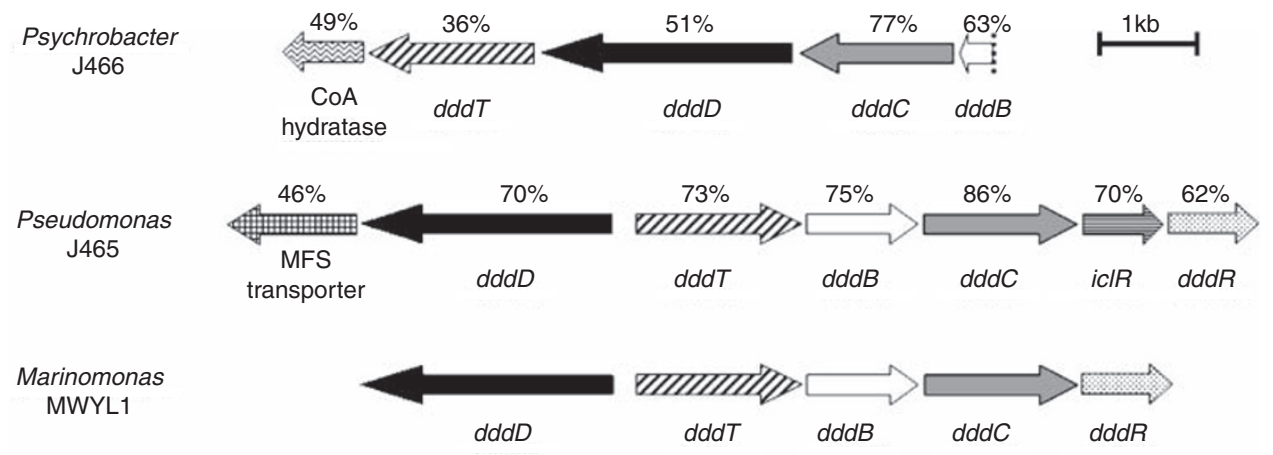

Figure 2 Arrangement of $d d d$ genes in Pseudomonas J465, Psychrobacter J466 and Marinomonas MWYL1. Genes previously identified as being involved in dimethylsulfoniopropionate (DMSP) catabolism ( $d d d)$ or that may be in the same transcriptional unit as $d d d$ genes are shown. The percentage identities of gene products to those of the corresponding genes in Marinomonas MWYL1 for $d d d T$, dddD, $d d d C, d d d B$ and $d d d R$ are shown, as are those of a CoA hydratase to that of Brevibacillus brevis NBRC 100599, of iclR to that of Colwellia psychrerythraea $34 \mathrm{H}$ and of the major facilitator transporter to that of marine $\gamma$-proteobacterium HTCC2207. The dashed vertical line indicates a breakpoint in $d d d B$ in the Psychrobacter library cosmid. Sequences are deposited at Genbank with accession numbers GQ370383, GQ370384, GQ370385 and GQ370386. 
in a process that liberates no DMS and which is effected by a gene, $d m d A$, which is widespread in marine bacteria (Howard et al., 2008). Further work is needed to determine the full range of bacterial types, and the relative contributions of different pathways involved in DMSP catabolism in these, and other animals. Top predators, such as procellariiform seabirds, penguins and harbour seals (Nevitt and Bonadonna, 2005; Kowalewsky et al., 2006; Cunningham et al., 2008) sense DMS as a chemoattractant, perhaps using it to find their prey, so it might even be in the fish's interest not to emit DMS, especially since the Herring may communicate at night by forming bubbles (of unknown chemical constitution) from their posteriors (Wilson et al., 2004).

This is the first report of DMSP-catabolizing bacteria in a vertebrate or in any animal at this trophic level, although such bacteria were found in guts of the copepod Acartia tonsa (Tang et al., 2001). $\mathrm{Ddd}^{+}$microbes may also occur in other marine carnivores including birds and cetaceans. It will be of interest to establish the contributions of such animals and their microflora to the global turnover of DMSP, since these may represent localized 'hotspots', analogous to (for example) coral reefs, which although small in total area, contribute disproportionately to the production and catabolism of DMSP (Jones and Trevena, 2005).

\section{Acknowledgements}

We thank Alyson Lumley and Robert Green for technical assistance. This work was funded by NERC and the BBSRC in the UK.

\section{References}

Ansede JH, Friedman RH, Yoch DC. (2001). Phylogenetic analysis of culturable dimethyl sulfide-producing bacteria from a Spartina-dominated salt marsh and estuarine water. Appl Environ Microbiol 67: 1210-1217.

Bozal N, Montes MJ, Mercadé E. (2007). Pseudomonas guineae sp. nov., a novel psychrotolerant bacterium from an Antarctic environment. Int J Syst Evol Microbiol 57: 2609-2612.

Cunningham GB, Strauss V, Ryan PG. (2008). African penguins (Spheniscus demersus) can detect dimethyl sulfide, a prey-related odour. J Exp Biol 211: 3123-3127.

Curson ARJ, Rogers R, Todd JD, Brearley CA, Johnston AWB. (2008). Molecular genetic analysis of a dimethylsulfoniopropionate lyase that liberates the climate-changing gas dimethylsulfide in several marine alpha-proteobacteria and Rhodobacter sphaeroides. Environ Microbiol 10: 757-767.

Hill RW, Dacey JWH. (2006). Metabolism of dimethylsulfoniopropionate (DMSP) by juvenile Atlantic menhaden Brevoortia tyrannus. Mar Ecol Progress Series 322: 239-248.
Hovda MB, Lunestad BT, Fontanillas R, Rosnes JT. (2007). Molecular characterisation of the intestinal microbiota of farmed Atlantic salmon (Salmo salar L.). Aquacult 272: 581-588.

Howard EC, Shulei S, Biers EJ, Moran MA. (2008). Abundant and diverse bacteria involved in DMSP degradation in marine surface waters. Environ Microbiol 10: 2397-2410.

Jones GB, Trevena AJ. (2005). The influence of coral reefs on atmospheric dimethylsulfide over the Great Barrier Reef, Coral Sea, Gulf of Papua, and Solomon and Bismarck Seas. Mar Fresh Water Res 56: 85-93.

Kowalewsky S, Dambach M, Mauck B, Dehnhardt G. (2006). High olfactory sensitivity for dimethyl sulphide in harbour seals. Biol Lett 2: 106-109.

Nevitt GA, Bonadonna F. (2005). Sensitivity to dimethyl sulphide suggests a mechanism for olfactory navigation by seabirds. Biol Lett 1: 303-305.

Raina JB, Tapiolas D, Willis BL, Bourne DG. (2009). Coralassociated bacteria and their role in the biogeochemical cycling of sulfur. Appl Environ Microbiol 75: 3492-3501.

Romanenko LA, Lysenko AM, Rohde M, Mikhailov VV, Stackebrandt E. (2004). Psychrobacter maritimus sp. nov. and Psychrobacter arenosus sp. nov. isolated form coastal ice and sediments of the Sea of Japan. Int J Syst Evol Microbiol 54: 1741-1745.

Schäfer H. (2007). Isolation of Methylophaga spp. from marine dimethylsulfide-degrading enrichment cultures and identification of polypeptides induced during growth on dimethylsulfide. Appl Environ Microbiol 73: 2580-2591.

Sievert SM, Kiene RP, Schulz-Vogt HN. (2007). The sulfur cycle. Oceanography 20: 117-123.

Tang KW, Visscher PT, Dam HG. (2001). DMSP-consuming bacteria associated with the calanoid copepod Acartia tonsa (Dana). J Exp Mar Bio Ecol 256: 185-198.

Todd JD, Rogers R, Li YG, Wexler M, Bond PL, Sun L et al. (2007). Structural and regulatory genes required to make the gas dimethyl sulfide in bacteria. Science 315: $666-669$.

Todd JD, Curson ARJ, Dupont CL, Nicholson P, Johnston AWB. (2009a). The $d d d P$ gene, encoding a novel enzyme that converts dimethylsulfoniopropionate into dimethyl sulfide, is widespread in ocean metagenomes and marine bacteria and also occurs in some Ascomycete fungi. Environ Microbiol 11: 1376-1385.

Todd JD, Curson ARJ, Nikolaidou-Katsaridou N, Brearley CA, Page PCB, Sun L et al. (2009b). Molecular dissection of bacterial acrylate catabolism-unexpected links with DMSP catabolism and dimethyl sulfide production. Environ Microbiol (in press).

Vallina SM, Simó R. (2007). Strong relationship between DMS and solar radiation dose over the global surface ocean. Science 315: 506-508.

Wilson B, Batty RS, Dill LM. (2004). Pacific and Atlantic herring produce pulse burst sounds. Biol Lett 271: S95-S97.

Yoch DC. (2002). Dimethylsulfoniopropionate: its sources, role in the marine food web, and biological degradation to dimethylsulfide. Appl Environ Microbiol 68: 5804-5815. 